\title{
The role of amyloid PET in patient selection for extra-ventricular shunt insertion for the treatment of idiopathic normal pressure hydrocephalus: a pooled analysis
}

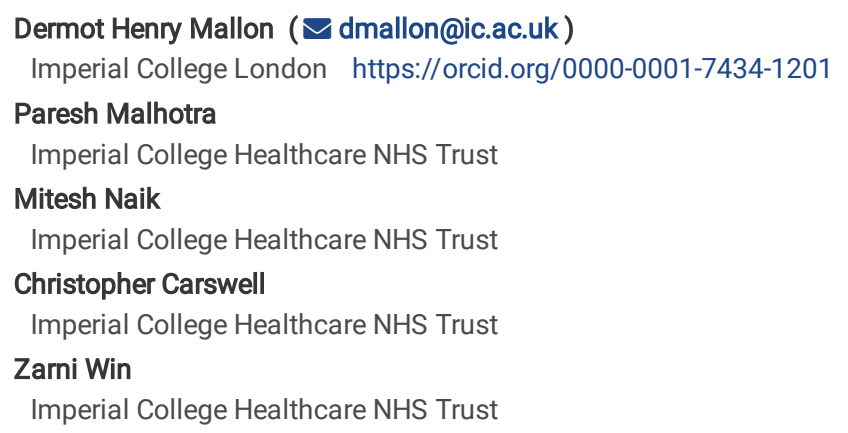




\section{Abstract}

Idiopathic Normal Pressure Hydrocephalus (iNPH) can be effectively treated through shunt insertion. However, most shunted patients experience little or no clinical benefit, which suggests suboptimal patient selection. While contentious, multiple studies have reported poorer shunt outcomes associated with concomitant Alzheimer's disease. Prompted by this observation, multiple studies have assessed the role of amyloid PET, a specific test for Alzheimer's disease, in patient selection for shunting.

Across three relevant studies, a total of 38 patients with suspected iNPH underwent amyloid PET imaging and shunt insertion. Twenty-one patients had a positive clinical response to shunting. $18 / 28(64.3 \%)$ of patients with a negative amyloid PET and $5 / 10(50 \%)$ with a positive amyloid PET had a positive response to shunting. The pooled sensitivity, specificity and accuracy was $33.3 \%, 76.2 \%$ and $58.3 \%$. None of these statistics reached statistical significance.

The results of this pooled analysis do not support the selection of patients with suspected iNPH for shunting on the basis of amyloid PET alone. However, due to small cohort sizes and weakness in study design, further high-quality studies are required to properly determine the role of amyloid PET in assessing this complex patient group.

\section{Introduction}

Idiopathic normal pressure hydrocephalus (iNPH) is a communicating hydrocephalus that causes a progressive syndrome typified by cognitive impairment, gait apraxia and urinary incontinence [1]. Ventriculomegaly develops despite normal CSF opening pressure on lumbar puncture. Disruption of normal CSF dynamics [2, 3], ciliary dysfunction [4], accumulation of toxic metabolites [5], reduced glymphatic drainage [6], and impaired cerebrovascular autoregulation [7], have all been implicated, but the pathogenesis of iNPH remains poorly understood.

Unlike most other causes of dementia which have no disease modifying treatment, iNPH can improve with CSF diversion [1]. Accurate patient selection is important due to the risk of serious complications. Haemorrhage, infection, over-drainage, obstruction and device failure occurs in $38 \%$ of patients [8, 9]. Permanent neurological sequalae or death occurs in $6 \%$ of patients [10].

Despite ongoing refinement of the iNPH diagnostic guidelines [11-15] and imaging criteria [16], patient selection is suboptimal. As few as 28\% of patients improve after shunting mainly due to the overlap in the clinical and imaging features of iNPH with other conditions, such as Alzheimer's disease (AD) and progressive supranuclear palsy [17], that are not treated with shunting.

The implications of AD pathology based on cortical biopsy or CSF analysis is contentious. Evidence of comorbid AD has been associated with poorer [18-22], similar $[23,24]$ and better [25] outcomes following CSF drainage. The discrepancy between these studies may be related to the biopsy of unrepresentative cerebral cortex or the reduced reliability of CSF analysis in patients with iNPH where toxic metabolic clearance is impaired [26].

There remains an unmet need for a non-invasive method of accurately identifying patients with shunt-responsive iNPH. Multiple structural imaging features are associated with shunt responsiveness [16, 27-31], however they are non-specific when considered in isolation. Increasingly complex MRI techniques have been used to augment patient selection for shunting, including Sylvian aqueduct CSF flow dynamics [32], dynamic contrast enhancement [33], water molecule diffusivity [34,35], elastography [36] and spectroscopy [37, 38], however none have been validated for routine clinical use.

The role of PET imaging in neurodegenerative disease has expanded massively [39-41]. For the assessment of AD, multiple radiotracers have been developed that cross the blood brain barrier to bind specifically to $A \beta[42]$. $A D$ can be reliably excluded by a normal uptake pattern of ${ }^{11} \mathrm{C}-\mathrm{Pittsburgh}$ Compound $B$ (PiB), ${ }^{18} \mathrm{~F}$-florbetapir (Amyvid) [43], ${ }^{18} \mathrm{~F}$-flutemetamol (Vizamyl) [44], and ${ }^{18} \mathrm{~F}$-florbetaben (Neuraceq) [45] (Figure 1).

Working on the hypothesis that amyloid deposition is associated with $A D$, which is associated with a poor response to shunting, multiple studies have examined the association between amyloid PET and clinical outcomes following shunt insertion in patients with suspected iNPH. In this article we present a pooled analysis of their results.

\section{Methods Study identification}

A comprehensive search was performed for human studies published in the English language between 1st January 1990 and 1 st September 2020 through electronic databases including MEDLINE, Embase, and Web of Science. A combination of keywords and MeSH terms were used, specifically "normal pressure hydrocephalus", “NPH”, “iNPH”, “Alzheimer's Disease”, "AD”, “amyloid”, “amyloid PET”, “amyloid radiotracer”, “CSF diversion”, “CSF tap test”, “extended lumbar drain", "shunt surgery" and "shunt response".

\section{Inclusion and exclusion criteria}

Studies were included if they reported the association between amyloid PET imaging findings and the response to a shunt in patients with suspected iNPH.

Studies were excluded if amyloid imaging was performed after shunting, if the decision to shunt was based on the amyloid PET result or if individual patient outcomes were not reported. 


\section{Data extraction}

Data extraction was performed independently by two readers with adjudication by a third, if necessary.

\section{Statistical analysis}

Results from individual studies were combined to pool estimates of sensitivity, specificity, negative predictive value, positive predictive value, and accuracy. Diagnostic statistics are presented as a percentage alongside the $95 \%$ confidence interval calculated using the Clopper-Pearson method. Numerical data are presented as a mean with the standard deviation, unless otherwise specified. Statistics were calculated using the statsmodels (version 0.12 ) package in Python 3.7.

\section{Results}

Three studies were identified that compared the clinical response to shunting between those with and without a positive amyloid PET scan [46-48].

Two further studies of amyloid PET performed before shunting were found but were excluded as the response to shunting was not reported [49, 50]. Additionally, both studies included patients from the same group and registry as one of the three studies that was already included. No detail was provided on any overlap in patient cohorts between these studies.

In a sixth study by Jang et al [51], the primary outcome was the association between CSF tap test and amyloid PET results. As only patients with a negative amyloid PET were offered a shunt, the study was excluded.

Details of the three studies that were included in the pooled analysis are provided in Table 1. The association between amyloid PET imaging and shunt response was the primary study outcome in a study by Hiraoka et al, whereas it was a secondary outcome in the other studies. Patients were recruited between approximately 2007 and 2016. In the study by Rinne et al, the recruitment period was not provided. Across all studies, 38 patients were shunted.

The technical detail of PET imaging including the choice of radiotracer is provided in Table $2 .{ }^{18} \mathrm{~F}$-flutemetamol was used in two studies and ${ }^{11} \mathrm{C}$-BF227 in one study.

Of the 38 patients shunted and followed-up, 23 had a positive clinical response. 18/28 (64.3\%) and 5/10 (50\%) of patients with a negative amyloid PET and positive amyloid PET had a positive response to shunting, respectively. The Fisher's exact test $P$ value for the association between shunt response and amyloid PET result was 0.473 .

The diagnostic statistics for the prediction of a shunt response in those with a negative amyloid PET is provided in Table 3 . Sensitivity, specificity and accuracy ranged from $0-60.0 \%, 60.0-87.5 \%$ and $52.9-72.7 \%$, respectively. The respective pooled sensitivity, specificity and accuracy was $33.3 \%$, $78.3 \%$ and $60.5 \%$

All three studies reported the SUVR (Standardised Uptake Value Ratio) for each patient, which are provided in Supplementary Table 1. The box and whisker plot in Figure 2 shows that SUVRs are generally higher in those who did not respond to shunting than those who did respond to shunting, although, neither individually nor when pooled, was the difference statistically significant.

Amyloid PET was well tolerated with only two cases of minor adverse reactions (nausea) reported by Rinne et al and four minor adverse reactions (dizziness, headache, abdominal pain, and throat irritation) by Leinonen et al. Hiraoka et al did not discuss adverse reactions.

\section{Discussion}

iNPH can be effectively treated through shunt insertion [52]. However, as many patients who undergo this procedure experience short-lived or no benefit from the procedure, patient selection is suboptimal. Prompted by reports of better shunt outcomes in those without evidence of AD [20, 53, 54], multiple studies have sought to determine how amyloid PET could improve patient selection. We present a pooled analysis of three non-randomised studies that have examined the association between amyloid PET and the clinical response to shunt insertion.

\section{Association between amyloid PET and shunt response}

The pooled results of the three studies shows low sensitivity (33.3\%) and a moderate specificity (78.3\%) in identifying patients with a poor response to shunting. Proportionally more patients who responded to a shunt had a negative amyloid PET than a positive amyloid PET (61.5\% versus $50 \%$ ), although the difference was not statistically significant. Therefore, the main finding in this pooled analysis is that amyloid PET, when considered in isolation, does not accurately identify patients with suspected iNPH who are likely to respond to shunting.

\section{Weaknesses of included studies}

There are multiple inherent weaknesses within the studies included in this pooled analysis. 
All of the studies were non-randomised and therefore inherit all of the limitations of such a study design. Furthermore, assessors of the clinical response to shunting were not blinded to the result of the amyloid PET, representing a potential source of bias.

All studies were small, yielding a total of only 38 patients. Therefore, each study was only powered to identify large effects. As such, differential effects on each component of the iNPH clinical triad could not be assessed. Similarly, in such small cohorts, it was not possible to control for other factors associated with shunt responsiveness, such as age [11,55], duration of symptoms [11,56-58], gait disturbance predominance over cognitive impairment [10,11, 57, 58], the presence of co-morbidities [55,59], and the structural imaging features of iNPH and AD.

In the study by Leinonen et al, amyloid imaging was performed between 9 and 38 months after the biopsy and shunt insertion. This is problematic because the effects of shunting on amyloid PET is unknown. Secondly, since amyloid deposition is progressive, the amyloid PET is likely to be an overestimate of the amyloid burden at the time the decision was taken to insert a shunt. Lastly, a significant interval between shunting and imaging may cause selection bias based on disease severity or, more significantly, the response to shunting.

In addition to these inherent weaknesses of the studies included in this pooled analysis, there was also significant variation between the studies in the clinical, radiological and non-radiological investigations performed, which has implications for pooling results.

Recruitment by Leinonen et a/ required only "enlarged ventricles" and any one of the iNPH clinical triad, whereas the other two studies also required sulcal effacement and two of the iNPH clinical triad. Leinonen et a/performed 24-hour intracranial pressure (ICP) monitoring in all patients before consideration of shunt insertion; in this study, all but one patient responded to shunting. Rinne et al used ICP monitoring "if required", although specific indications were not discussed. Hiraoka et al performed CSF tap testing. As inclusion criteria become less stringent, the pre-test probability for iNPH decreases and so does the expected response rate to shunting.

The method of assessing the clinical response to shunting was variable. Methods included the iNPHGS [60], the Black score [61] or a non-disclosed "clinical assessment". Different methods are likely to influence the reported rate of shunt response, which has obvious implications when pooling results. Furthermore, the timing of the assessment ranged from 2 months to over 20 months. Clinical improvement may occur over many months, which is reflected in the ongoing changes in the parenchyma and CSF spares through the first postoperative year [62]. On the other hand, clinical improvements can be fleeting [63-65] and therefore follow-up of at least one year is often used in clinical trials [66]. In two of the studies, assessment was performed at three months or earlier. The value of a clinical improvement lasting three months is debatable, and, in many centres, this would be considered unsatisfactory.

Two different radiotracers were used in the three studies. Multiple radiotracers have been developed with differing pharmacokinetics although all are highly specific for $A \beta$ [67] and correlation between radiotracer uptake is high [68-70]. Therefore, the diagnostic accuracy of different amyloid-specific radiotracers, and hence their role in patient selection for shunt insertion, is likely to be comparable.

\section{Reasons for lack of association between amyloid PET and shunt response}

Firstly, amyloid PET may accumulate in the brain for reasons that have no effect on shunt response. While A $\beta$ deposition, alongside hyperphosphorylated tau protein, is a histopathological hallmark of AD [71], it is also observed in other neurodegenerative conditions such as Lewy Body Dementia [72, 73] and cerebral amyloid angiopathy [74]. Amyloid deposition also occurs in healthy aging [75-77], albeit with an increased risk of subsequent cognitive decline [78, 79]. Secondly, the potential for improvement post-shunting will depend on the degree of permanent neurological damage caused by NPH or any other comorbid condition [80]. Thirdly, a recent study showed CSF biomarkers of AD were associated with a positive response to tap-test [25]. This observation raises the possibility of a so-called neurodegenerative NPH (that would be amyloid PET positive) that is separate from an idiopathic NPH. Despite the result of this pooled analysis, amyloid PET may still have a role in the wider workup of patients for shunt insertion, particularly in identifying dual pathology. Even if amyloid PET does not predict immediate shunt outcomes, cerebral amyloid is likely to influence long-term prognosis, which would be relevant when counselling patients on the expected risks and benefits of shunt insertion.

\section{Requirements for future study}

There remains a need for a blinded and randomized study to definitively determine the role of qualitative and quantitative interpretation of amyloid PET in predicting shunt response in patients with suspected iNPH. The study should be adequately powered to assess for differential effects of each domain of iNPH and to control for disease severity and other clinical features associated with long-term shunt outcomes. The predictive power of amyloid PET should be compared with the features apparent on structural imaging and biomarkers from CSF analysis. Finally, adequate follow-up of at least a year is required due to the progressive nature of $A D$ and the often-transient improvements experienced following shunting.

\section{Conclusion}

This pooled analysis does not support the use of amyloid PET in the selection of patients with suspected iNPH for shunting. Amyloid PET may however remain a useful adjunct in the workup of these patients, specifically for informing longer term prognosis. There remains the need for higher quality prospective studies to more conclusively evaluate the role of amyloid PET in this complex patient group.

\section{Declarations}

\section{Ethics approval and consent to participate}

Page 4/12 
Not applicable.

\section{Consent for publication}

Not applicable.

\section{Availability of data and materials}

Not applicable.

\section{Competing interests}

Nil.

\section{Funding}

DHM is supported by the Imperial Health Charity and National Institute for Health Research Biomedical Research Centre based at Imperial College Healthcare NHS Trust and Imperial College London.

\section{Authors' contributions}

\begin{tabular}{|ll|}
\hline Dermot H. Mallon & Study design, statistical analysis, manuscript drafting, manuscript review and editing \\
\hline Paresh Malhotra & Manuscript review and editing \\
\hline Mitesh Naik & Manuscript drafting, manuscript review and editing \\
\hline Christopher Carswell* & Study design, manuscript review and editing \\
\hline Zarni Win* & Study design, manuscript review and editing \\
\hline
\end{tabular}

* Equal contribution

\section{Acknowledgements}

Nil.

\section{References}

1. Adams RD, Fisher CM, Hakim S, et al (1965) Symptomatic Occult Hydrocephalus with Normal Cerebrospinal-Fluid Pressure. N Engl J Med 273:117-126. https://doi.org/10.1056/NEJM196507152730301

2. Silverberg GD (2004) Normal pressure hydrocephalus (NPH): ischaemia, CSF stagnation or both. Brain 127:947-948. https://doi.org/10.1093/brain/awh178

3. Korhonen VE, Helisalmi S, Jokinen A, et al (2018) Copy number loss in SFMBT1 is common among Finnish and Norwegian patients with iNPH. Neurol Genet 4:e291. https://doi.org/10.1212/NXG.0000000000000291

4. Morimoto Y, Yoshida S, Kinoshita A, et al (2019) Nonsense mutation in CFAP43 causes normal-pressure hydrocephalus with ciliary abnormalities. Neurology 92:e2364-e2374. https://doi.org/10.1212/WNL.0000000000007505

5. Silverberg GD, Mayo M, Saul T, et al (2003) Alzheimer's disease, normal-pressure hydrocephalus, and senescent changes in CSF circulatory physiology: a hypothesis. Lancet Neurol 2:506-11. https://doi.org/10.1016/s1474-4422(03)00487-3

6. Ringstad G, Vatnehol SAS, Eide PK (2017) Glymphatic MRI in idiopathic normal pressure hydrocephalus. Brain 140:2691-2705. https://doi.org/10.1093/brain/awx191

7. Momjian S, Owler BK, Czosnyka Z, et al (2004) Pattern of white matter regional cerebral blood flow and autoregulation in normal pressure hydrocephalus. Brain 127:965-972. https://doi.org/10.1093/brain/awh131

8. Toma AK, Papadopoulos MC, Stapleton S, et al (2013) Systematic review of the outcome of shunt surgery in idiopathic normal-pressure hydrocephalus. Acta Neurochir (Wien) 155:1977-1980. https://doi.org/10.1007/s00701-013-1835-5

9. D'antona L, Blamey SC, Craven CL, et al (2019) Early Postoperative Outcomes of Normal Pressure Hydrocephalus: Results of a Service Evaluation. J Neurosurg Anesthesiol. https://doi.org/10.1097/ANA.0000000000000668

10. Hebb AO, Cusimano MD (2001) Idiopathic normal pressure hydrocephalus: a systematic review of diagnosis and outcome. Neurosurgery 49:1166-84; discussion 1184-6. https://doi.org/10.1097/00006123-200111000-00028 
11. Marmarou A, Bergsneider M, Relkin N, et al (2005) INPH guidelines, part I: Development of guidelines for idiopathic normal-pressure hydrocephalus: Introduction. Neurosurgery 57:2-4. https://doi.org/10.1227/01.NEU.0000168188.25559.0E

12. Mori E, Ishikawa M, Kato T, et al (2012) Guidelines for management of idiopathic normal pressure hydrocephalus: Second edition. Neurol Med Chir (Tokyo) 52:775-778. https://doi.org/10.2176/nmc.52.775

13. Williams MA, Relkin NR (2013) Diagnosis and management of idiopathic normal-pressure hydrocephalus. Neurol Clin Pract 3:375-385. https://doi.org/10.1212/CPJ.0b013e3182a78f6b

14. Andersson J, Rosell M, Kockum K, et al (2017) Challenges in diagnosing normal pressure hydrocephalus: Evaluation of the diagnostic guidelines. eNeurologicalSci 7:27-31. https://doi.org/10.1016/j.ensci.2017.04.002

15. Espay AJ, Da Prat GA, Dwivedi AK, et al (2017) Deconstructing normal pressure hydrocephalus: Ventriculomegaly as early sign of neurodegeneration. Ann Neurol 82:503-513. https://doi.org/10.1002/ana.25046

16. Kockum K, Virhammar J, Riklund K, et al (2020) Diagnostic accuracy of the iNPH Radscale in idiopathic normal pressure hydrocephalus. PLoS One 15:110. https://doi.org/10.1371/journal.pone.0232275

17. Constantinides VC, Paraskevas GP, Velonakis G, et al (2020) Midbrain morphology in idiopathic normal pressure hydrocephalus: A progressive supranuclear palsy mimic. Acta Neurol Scand 141:328-334. https://doi.org/10.1111/ane.13205

18. Bech-Azeddine R, Høgh P, Juhler M, et al (2007) Idiopathic normal-pressure hydrocephalus: Clinical comorbidity correlated with cerebral biopsy findings and outcome of cerebrospinal fluid shunting. J Neurol Neurosurg Psychiatry 78:157-161. https://doi.org/10.1136/jnnp.2006.095117

19. Leinonen V, Koivisto AM, Alafuzoff I, et al (2012) Cortical Brain Biopsy in Long-Term Prognostication of 468 Patients with Possible Normal Pressure Hydrocephalus. Neurodegener Dis 10:166-169. https://doi.org/10.1159/000335155

20. Hamilton R, Patel S, Lee EB, et al (2010) Lack of shunt response in suspected idiopathic normal pressure hydrocephalus with Alzheimer disease pathology. Ann Neurol 68:535-540. https://doi.org/10.1002/ana.22015

21. Allali G, Laidet M, Armand S, Assal F (2018) Brain comorbidities in normal pressure hydrocephalus. Eur J Neurol 25:542-548. https://doi.org/10.1111/ene.13543

22. Patel S, Lee EB, Xie SX, et al (2012) Phosphorylated tau/amyloid beta 1-42 ratio in ventricular cerebrospinal fluid reflects outcome in idiopathic normal pressure hydrocephalus. Fluids Barriers CNS 9:7. https://doi.org/10.1186/2045-8118-9-7

23. Yasar S, Jusue-Torres I, Lu J, et al (2017) Alzheimer's disease pathology and shunt surgery outcome in normal pressure hydrocephalus. PLoS One 12:111. https://doi.org/10.1371/journal.pone.0182288

24. Golomb J, Wisoff J, Miller DC, et al (2000) Alzheimer's disease comorbidity in normal pressure hydrocephalus: Prevalence and shunt response. J Neurol Neurosurg Psychiatry 68:778-781. https://doi.org/10.1136/jnnp.68.6.778

25. Müller-Schmitz K, Krasavina-Loka N, Yardimci T, et al (2020) Normal Pressure Hydrocephalus Associated with Alzheimer's Disease. Ann Neurol 88:703711. https://doi.org/10.1002/ana.25847

26. Graff-Radford NR (2014) Alzheimer CSF biomarkers may be misleading in normal-pressure hydrocephalus. Neurology 83:1573-1575. https://doi.org/10.1212/WNL.0000000000000916

27. Toma AK, Holl E, Kitchen ND, Watkins LD (2011) Evans' index revisited: The need for an alternative in normal pressure hydrocephalus. Neurosurgery 68:939-944. https://doi.org/10.1227/NEU.0b013e318208f5e0

28. Hashimoto M, Ishikawa M, Mori E, Kuwana N (2010) Diagnosis of idiopathic normal pressure hydrocephalus is supported by MRI-based scheme: A prospective cohort study. Cerebrospinal Fluid Res 7:. https://doi.org/10.1186/1743-8454-7-18

29. Narita W, Nishio Y, Baba T, et al (2016) High-convexity tightness predicts the shunt response in idiopathic normal pressure hydrocephalus. Am J Neuroradiol 37:1831-1837. https://doi.org/10.3174/ajnr.A4838

30. Ishii K, Kanda T, Harada A, et al (2008) Clinical impact of the callosal angle in the diagnosis of idiopathic normal pressure hydrocephalus. Eur Radiol 18:2678-2683. https://doi.org/10.1007/s00330-008-1044-4

31. Virhammar J, Laurell K, Cesarini KG, Larsson EM (2014) The callosal angle measured on MRI as a predictor of outcome in idiopathic normal-pressure hydrocephalus. Clinical article. J Neurosurg. https://doi.org/10.3171/2013.8.JNS13575

32. Bradley WG, Scalzo D, Queralt J, et al (1996) Normal-pressure hydrocephalus: evaluation with cerebrospinal fluid flow measurements at MR imaging. Radiology 198:523-9. https://doi.org/10.1148/radiology.198.2.8596861

33. Ziegelitz D, Starck G, Kristiansen D, et al (2014) Cerebral perfusion measured by dynamic susceptibility contrast MRI is reduced in patients with idiopathic normal pressure hydrocephalus. J Magn Reson Imaging 39:1533-1542. https://doi.org/10.1002/jmri.24292

34. Ivkovic M, Liu B, Ahmed F, et al (2013) Differential diagnosis of normal pressure hydrocephalus by MRI mean diffusivity histogram analysis. AJNR Am J Neuroradiol 34:1168-74. https://doi.org/10.3174/ajnr.A3368

35. Hattori T, Yuasa T, Aoki S, et al (2011) Altered microstructure in corticospinal tract in idiopathic normal pressure hydrocephalus: comparison with Alzheimer disease and Parkinson disease with dementia. AJNR Am J Neuroradiol 32:1681-7. https://doi.org/10.3174/ajnr.A2570

36. Freimann FB, Streitberger K-J, Klatt D, et al (2012) Alteration of brain viscoelasticity after shunt treatment in normal pressure hydrocephalus. Neuroradiology 54:189-196. https://doi.org/10.1007/s00234-011-0871-1

37. Kizu O, Yamada K, Nishimura T (2001) Proton chemical shift imaging in normal pressure hydrocephalus. Am J Neuroradiol

38. Algin O, Hakyemez B, Parlak M (2010) Proton MR spectroscopy and white matter hyperintensities in idiopathic normal pressure hydrocephalus and other dementias. Br J Radiol 83:747-752. https://doi.org/10.1259/bjr/43131041 
39. Ishii K (2014) PET Approaches for Diagnosis of Dementia. Am J Neuroradiol 35:2030-2038. https://doi.org/10.3174/ajnr.A3695

40. Marcus C, Mena E, Subramaniam RM (2014) Brain PET in the diagnosis of Alzheimer's disease. Clin Nucl Med 39:e413-e426. https://doi.org/10.1097/RLU.0000000000000547

41. Mattoli MV, Treglia G, Calcagni ML, et al (2020) Usefulness of brain positron emission tomography with different tracers in the evaluation of patients with idiopathic normal pressure hydrocephalous. Int J Mol Sci 21:1-22. https://doi.org/10.3390/ijms21186523

42. Secondary CA, Author C, Dumba M, et al (2019) Clinical 18F-FDG and amyloid brain positron emission tomography/CT in the investigation of cognitive impairment: Where are we now? Br J Radiol 92:. https://doi.org/10.1259/bjr.20181027

43. Wong DF, Rosenberg PB, Zhou Y, et al (2010) In Vivo Imaging of Amyloid Deposition in Alzheimer Disease Using the Radioligand $18 \mathrm{~F}-\mathrm{AV}-45$ (Flobetapir $F$ 18). J Nucl Med 51:913-920. https://doi.org/10.2967/jnumed.109.069088

44. Rinne JO, Wong DF, Wolk DA, et al (2012) Flutemetamol PET imaging and cortical biopsy histopathology for fibrillar amyloid $\beta$ detection in living subjects with normal pressure hydrocephalus: Pooled analysis of four studies. Acta Neuropathol 124:833-845. https://doi.org/10.1007/s00401-012-1051-z

45. Rowe CC, Ackerman U, Browne W, et al (2008) Imaging of amyloid $\beta$ in Alzheimer's disease with 18F-BAY94-9172, a novel PET tracer: proof of mechanism. Lancet Neurol 7:129-135. https://doi.org/10.1016/S1474-4422(08)70001-2

46. Leinonen V, Rinne JO, Virtanen KA, et al (2013) Positron emission tomography with [18F]flutemetamol and [11C]PiB for in vivo detection of cerebral cortical amyloid in normal pressure hydrocephalus patients. Eur J Neurol 20:1043-1052. https://doi.org/10.1111/ene.12102

47. Rinne JO, Frantzen J, Leinonen V, et al (2014) Prospective flutemetamol positron emission tomography and histopathology in normal pressure hydrocephalus. Neurodegener Dis 13:237-245. https://doi.org/10.1159/000355256

48. Hiraoka K, Narita W, Kikuchi H, et al (2015) Amyloid deposits and response to shunt surgery in idiopathic normal-pressure hydrocephalus. J Neurol Sci 356:124-128. https://doi.org/10.1016/j.jns.2015.06.029

49. Leinonen V, Rauramaa T, Johansson J, et al (2018) S-[18F]THK-5117-PET and [11C]PIB-PET Imaging in Idiopathic Normal Pressure Hydrocephalus in Relation to Confirmed Amyloid- $\beta$ Plaques and Tau in Brain Biopsies. J Alzheimers Dis 64:171-179. https://doi.org/10.3233/JAD-180071

50. Rinne JO, Suotunen T, Rummukainen J, et al (2019) [11C]PIB PET Is Associated with the Brain Biopsy Amyloid- $\beta$ Load in Subjects Examined for Normal Pressure Hydrocephalus. J Alzheimers Dis 67:1343-1351. https://doi.org/10.3233/JAD-180645

51. Jang H, Park SB, Kim Y, et al (2018) Prognostic value of amyloid PET scan in normal pressure hydrocephalus. J Neurol 265:63-73. https://doi.org/10.1007/s00415-017-8650-5

52. Leinonen V, Koivisto AM, Savolainen S, et al (2010) Amyloid and tau proteins in cortical brain biopsy and Alzheimer's disease. Ann Neurol 68:446-453. https://doi.org/10.1002/ana.22100

53. Lim TS, Choi JY, Park SA, et al (2014) Evaluation of coexistence of Alzheimer's disease in idiopathic normal pressure hydrocephalus using ELISA analyses for CSF biomarkers. BMC Neurol 14:66. https://doi.org/10.1186/1471-2377-14-66

54. Hamdeh SA, Virhammar J, Sehlin D, et al (2019) Brain tissue A 342 levels are linked to shunt response in idiopathic normal pressure hydrocephalus. J Neurosurg 130:121-129. https://doi.org/10.3171/2017.7.JNS171005

55. Bådagård H, Braun M, Nilsson D, et al (2020) Negative predictors of shunt surgery outcome in normal pressure hydrocephalus. Acta Neurol Scand 141:219-225. https://doi.org/10.1111/ane.13200

56. Meier U, Miethke C (2003) Predictors of outcome in patients with normal-pressure hydrocephalus. J Clin Neurosci 10:453-9. https://doi.org/10.1016/s0967-5868(03)00079-1

57. Graff-Radford NR, Godersky JC, Jones MP (1989) Variables predicting surgical outcome in symptomatic hydrocephalus in the elderly. Neurology 39:1601-4. https://doi.org/10.1212/wnl.39.12.1601

58. Wu EM, El Ahmadieh TY, Kafka B, et al (2019) Ventriculoperitoneal Shunt Outcomes of Normal Pressure Hydrocephalus: A Case Series of 116 Patients. Cureus 11:e4170. https://doi.org/10.7759/cureus.4170

59. Kiefer M, Eymann R, Steudel WI (2006) Outcome predictors for normal-pressure hydrocephalus. Acta Neurochir Suppl 96:364-7. https://doi.org/10.1007/3-211-30714-1_75

60. Kubo Y, Kazui H, Yoshida T, et al (2008) Validation of grading scale for evaluating symptoms of idiopathic normal-pressure hydrocephalus. Dement Geriatr Cogn Disord 25:37-45. https://doi.org/10.1159/000111149

61. Black PM (1980) Idiopathic normal-pressure hydrocephalus. Results of shunting in 62 patients. J Neurosurg 52:371-7. https://doi.org/10.3171/jns.1980.52.3.0371

62. Yamada S, Ishikawa M, Yamaguchi M, Yamamoto K (2019) Longitudinal morphological changes during recovery from brain deformation due to idiopathic normal pressure hydrocephalus after ventriculoperitoneal shunt surgery. Sci Rep 9:1-13. https://doi.org/10.1038/s41598-019-53888-7

63. Aygok G, Marmarou A, Young HF Three-year outcome of shunted idiopathic NPH patients. In: Intracranial Pressure and Brain Monitoring XII. SpringerVerlag, Vienna, pp 241-245

64. Raftopoulos C, Deleval J, Chaskis C, et al (1994) Cognitive Recovery in Idiopathic Normal Pressure Hydrocephalus. Neurosurgery 35:397-405. https://doi.org/10.1227/00006123-199409000-00006

65. Shaw R, Everingham E, Mahant N, et al (2016) Clinical outcomes in the surgical treatment of idiopathic normal pressure hydrocephalus. J Clin Neurosci 29:81-86. https://doi.org/10.1016/j.jocn.2015.10.044

66. Kazui H, Kanemoto H, Yoshiyama K, et al (2016) Association between high biomarker probability of Alzheimer's disease and improvement of clinical outcomes after shunt surgery in patients with idiopathic normal pressure hydrocephalus. J Neurol Sci 369:236-241.

https://doi.org/10.1016/j.jns.2016.08.040

Page 7/12 
67. Fodero-Tavoletti MT, Mulligan RS, Okamura N, et al (2009) In vitro characterisation of BF227 binding to a-synuclein/Lewy bodies. Eur J Pharmacol 617:54-58. https://doi.org/10.1016/j.ejphar.2009.06.042

68. Knesaurek K, Warnock G, Kostakoglu L, et al (2018) Comparison of standardized uptake value ratio calculations in amyloid positron emission tomography brain imaging. World J Nucl Med 17:21. https://doi.org/10.4103/wjnm.WJNM_5_17

69. Hatashita S, Wakebe D, Kikuchi Y, Ichijo A (2019) Longitudinal Assessment of Amyloid- $\beta$ Deposition by [18F]-Flutemetamol PET Imaging Compared With [11C]-PIB Across the Spectrum of Alzheimer's Disease. Front Aging Neurosci 11:251. https://doi.org/10.3389/fnagi.2019.00251

70. Mountz JM, Laymon CM, Cohen AD, et al (2015) Comparison of qualitative and quantitative imaging characteristics of [ $11 \mathrm{C}$ ]PiB and [ $18 \mathrm{~F}$ ]flutemetamol in normal control and Alzheimer's subjects. Neurolmage Clin 9:592-598. https://doi.org/10.1016/j.nicl.2015.10.007

71. Thal DR, Rüb U, Orantes M, Braak H (2002) Phases of A -deposition in the human brain and its relevance for the development of AD. Neurology. https://doi.org/10.1212/WNL.58.12.1791

72. Gomperts SN, Locascio JJ, Marquie M, et al (2012) Brain amyloid and cognition in Lewy body diseases. Mov Disord 27:965-73. https://doi.org/10.1002/mds.25048

73. Kantarci K, Lowe VJ, Chen Q, et al (2020) ß-Amyloid PET and neuropathology in dementia with Lewy bodies. Neurology 94:e282-e291. https://doi.org/10.1212/WNL.0000000000008818

74. Charidimou A, Farid K, Tsai H-H, et al (2018) Amyloid-PET burden and regional distribution in cerebral amyloid angiopathy: a systematic review and metaanalysis of biomarker performance. J Neurol Neurosurg Psychiatry 89:410-417. https://doi.org/10.1136/jnnp-2017-316851

75. Rodrigue KM, Kennedy KM, Devous MD, et al (2012) -Amyloid burden in healthy aging: Regional distribution and cognitive consequences. Neurology 78:387-395. https://doi.org/10.1212/WNL.0b013e318245d295

76. Chételat G, La Joie R, Villain N, et al (2013) Amyloid imaging in cognitively normal individuals, at-risk populations and preclinical Alzheimer's disease. Neurolmage Clin 2:356-365. https://doi.org/10.1016/j.nicl.2013.02.006

77. Reas ET (2017) Amyloid and Tau Pathology in Normal Cognitive Aging. J Neurosci 37:7561-7563. https://doi.org/10.1523/JNEUROSCl.1388-17.2017

78. Guo T, Landau SM, Jagust WJ (2020) Detecting earlier stages of amyloid deposition using PET in cognitively normal elderly adults. Neurology $94:$ e1512e1524. https://doi.org/10.1212/WNL.0000000000009216

79. Doraiswamy PM, Sperling RA, Johnson K, et al (2014) Florbetapir F 18 amyloid PET and 36-month cognitive decline:a prospective multicenter study. Mol Psychiatry 19:1044-1051. https://doi.org/10.1038/mp.2014.9

80. Iddon JL, Pickard JD, Cross JJ, et al (1999) Specific patterns of cognitive impairment in patients with idiopathic normal pressure hydrocephalus and Alzheimer's disease: a pilot study. J Neurol Neurosurg Psychiatry 67:723-32. https://doi.org/10.1136/jnnp.67.6.723

\section{Tables}

Table 1: Summary of studies included in the pooled analysis. 


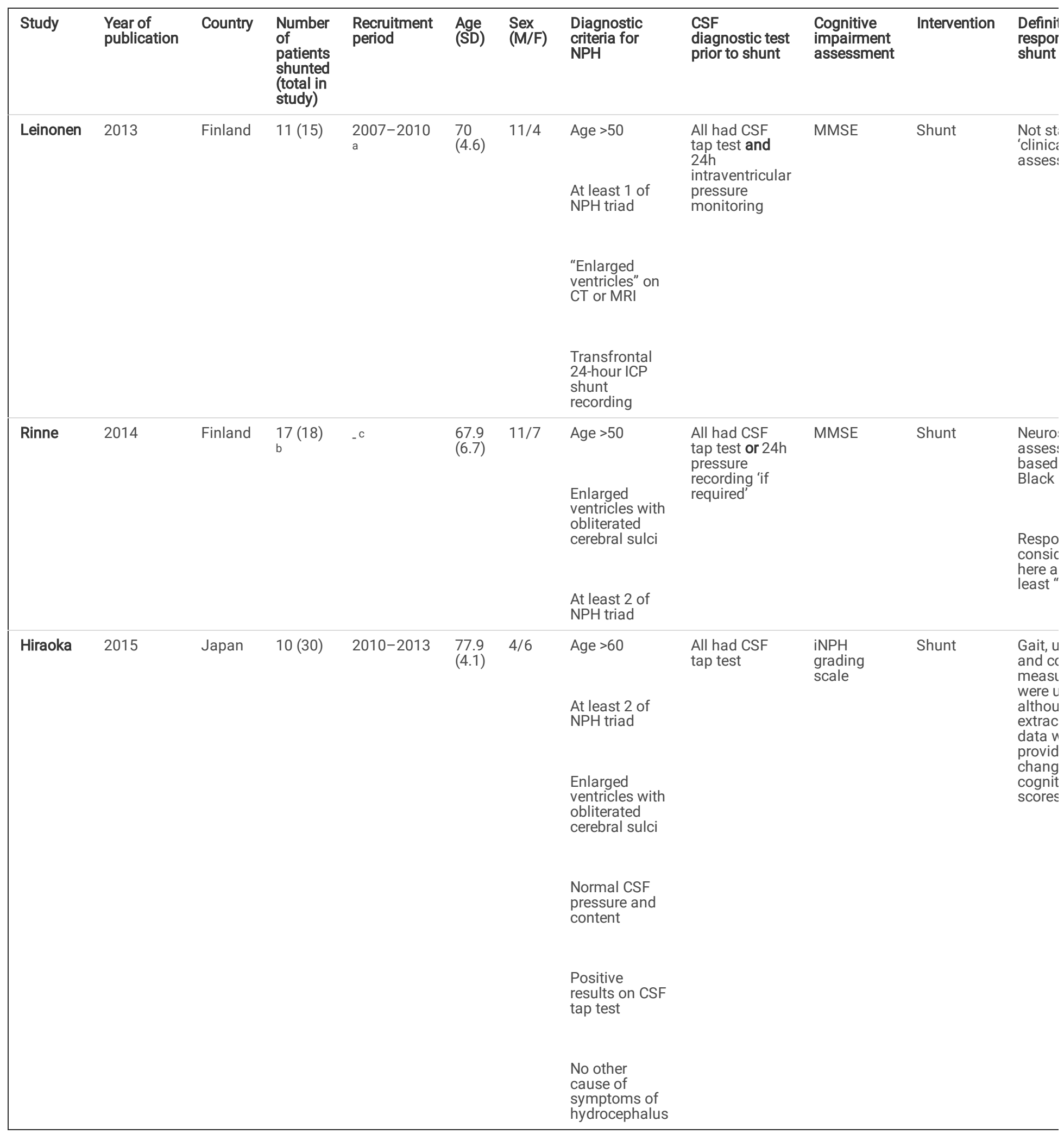

${ }^{\text {a }}$ Recruitment dates not stated in article. Full cohort from Leinonen et al (2010). Start of recruitment given as 2007 , the year in which ${ }^{18} \mathrm{~F}$-flutemetamol was developed. ${ }^{\mathrm{b}} 17$ patients followed up due to patient death for cause unrelated to shunting. ${ }^{\mathrm{c}}$ Recruitment dates not stated in article.

Table 2: Technical detail of the amyloid PET scan. 


\begin{tabular}{|llllll|}
\hline Study & Radiotracer & Dose (MBq) & Uptake time & Acquisition time & Amyloid PET assessment \\
\hline Leinonen & ${ }^{18}$ F-flutemetamol $^{\text {a }}$ & $174($ SD 3.4) & 90 & 30 & Qualitative \\
\hline Rinne & ${ }^{18}$ F-flutemetamol & 176 (range 169-184) & 90 & 30 & Qualitative \\
\hline Hiraoka & ${ }^{11}$ C-BF227 & - b & 90 & 60 (dynamic acquisition) $^{\text {Quantitative }^{c}}$ \\
\hline
\end{tabular}

${ }^{18} \mathrm{~F}$-flutemetamol was used in all patients and therefore the results of this were used to calculate diagnostic statistics; PiB (C11) was used in a subset of 7 patients. ${ }^{\mathrm{b}}$ Radiation dose not provided. ${ }^{\mathrm{c}}$ SUVR of 1.15 was defined by lowest SUVR value within a confirmed AD group.

Table 3: Pooled diagnostic accuracy of Amyloid PET identifying patients that do not have a clinical response to shunting.

\begin{tabular}{|c|c|c|c|c|c|c|c|c|c|c|}
\hline \multirow[t]{2}{*}{ Study } & \multicolumn{2}{|c|}{ Amyloid PET positive } & \multicolumn{2}{|c|}{ Amyloid PET negative } & \multirow[t]{2}{*}{$P^{a}$} & \multirow[t]{2}{*}{ Sensitivity } & \multirow[t]{2}{*}{ Specificity } & \multirow[t]{2}{*}{ PPV } & \multirow[t]{2}{*}{ NPV } & \multirow[t]{2}{*}{ Accuracy } \\
\hline & $\begin{array}{l}\text { No shunt } \\
\text { response } \\
\text { (TP) }\end{array}$ & $\begin{array}{l}\text { Shunt } \\
\text { response } \\
\text { (FP) }\end{array}$ & $\begin{array}{l}\text { No shunt } \\
\text { response } \\
\text { (FN) }\end{array}$ & $\begin{array}{l}\text { Shunt } \\
\text { response } \\
\text { (TN) }\end{array}$ & & & & & & \\
\hline Leinonen & 0 & 2 & 1 & 8 & 1.000 & $\begin{array}{l}0.0(0.0- \\
97.5)\end{array}$ & $\begin{array}{l}80.0 \\
(44.4- \\
97.5)\end{array}$ & - & $\begin{array}{l}88.9 \\
(85.4- \\
91.6)\end{array}$ & $\begin{array}{l}72.7 \\
(39.0- \\
94.0)\end{array}$ \\
\hline Rinne & 2 & 1 & 7 & 7 & 1.000 & $\begin{array}{l}22.2(2.8- \\
60.0)\end{array}$ & $\begin{array}{l}87.5 \\
(47.4- \\
99.7)\end{array}$ & $\begin{array}{l}66.7 \\
(18.1- \\
94.8)\end{array}$ & $\begin{array}{l}50.0 \\
(39.3- \\
60.7)\end{array}$ & $\begin{array}{l}52.9 \\
(27.8- \\
77.0)\end{array}$ \\
\hline Hiraoka & 3 & 2 & 2 & 3 & 1.000 & $\begin{array}{l}60.0 \\
(14.7- \\
94.7)\end{array}$ & $\begin{array}{l}60.0 \\
(14.7- \\
94.7)\end{array}$ & $\begin{array}{l}60.0 \\
(29.2- \\
84.5)\end{array}$ & $\begin{array}{l}60.0 \\
(29.2- \\
84.5)\end{array}$ & $\begin{array}{l}60.0 \\
(26.2- \\
87.8)\end{array}$ \\
\hline Pooled & 5 & 5 & 10 & 18 & 0.473 & $\begin{array}{l}33.3 \\
(11.8- \\
61.6)\end{array}$ & $\begin{array}{l}78.3 \\
(56.3- \\
92.5)\end{array}$ & $\begin{array}{l}50.0 \\
(25.8- \\
74.2)\end{array}$ & $\begin{array}{l}64.3 \\
(54.2- \\
73.2)\end{array}$ & $\begin{array}{l}60.5 \\
(43.4- \\
76.0)\end{array}$ \\
\hline
\end{tabular}

\footnotetext{
a Fisher's exact test.
}

\section{Figures}



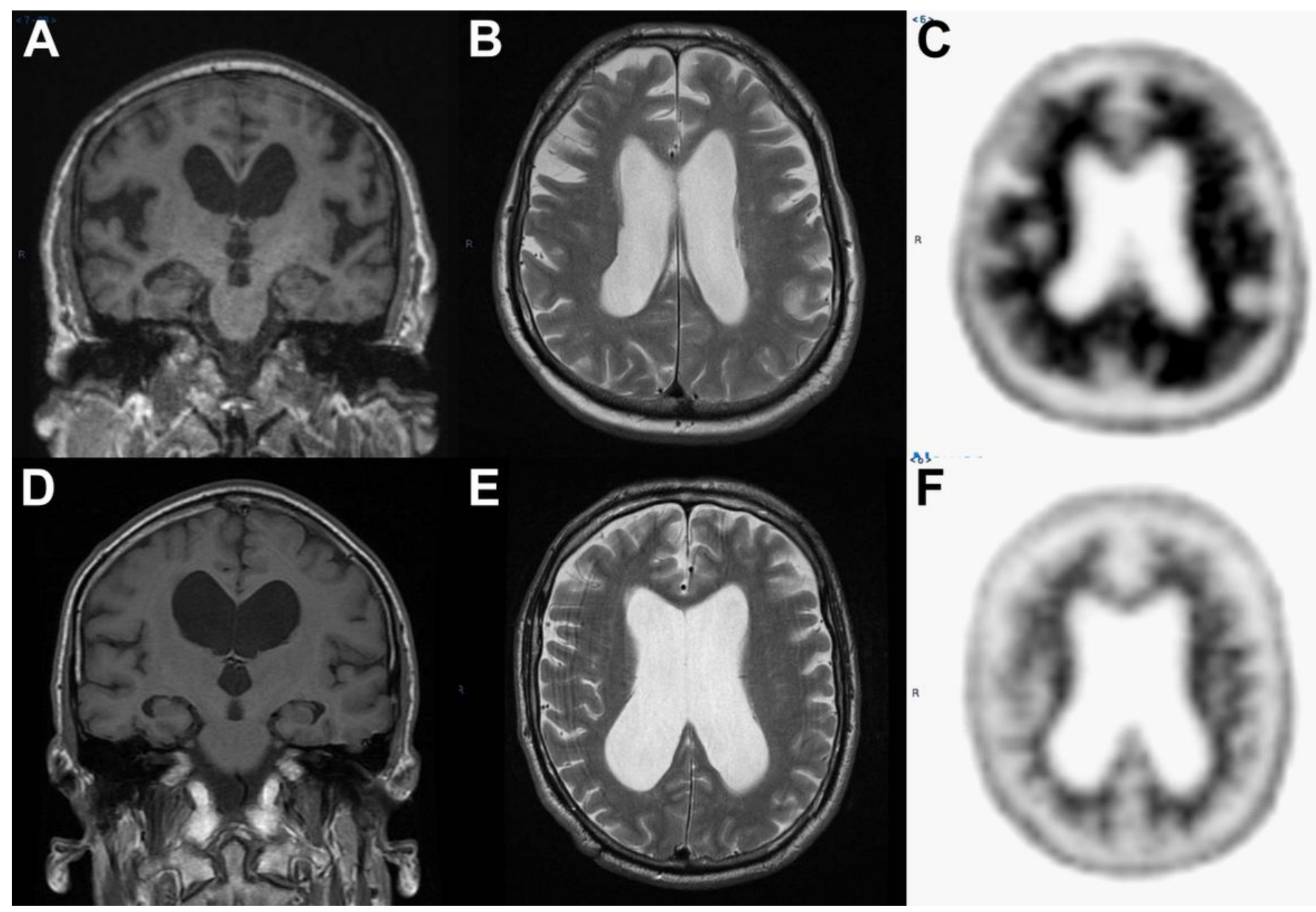

Figure 1

Imaging features of normal pressure hydrocephalus and Alzheimer's disease. In a 70-year-old patient who presenting with cognitive decline, the coronal T1weighted imaging (A) and axial T2-weighted MR imaging (B), suggested normal pressure hydrocephalus due to ventriculomegaly and crowding near the vertex. However, the 18F-florbetapir PET imaging (C) showed generalised increased grey matter uptake with loss of grey-white matter differentiation, particularly within the bilateral posterior parietal cortices. This signified extensive amyloid deposition prompting a diagnosis of Alzheimer's disease. Conversely, in a 67-year-old patient also with ventriculomegaly on MR imaging (D, E), the 18F-florbetapir PET imaging showed a normal pattern of uptake and preserved grey-white matter differentiation indicating no significant amyloid deposition. This patient had a significant and sustained response to shunting. 


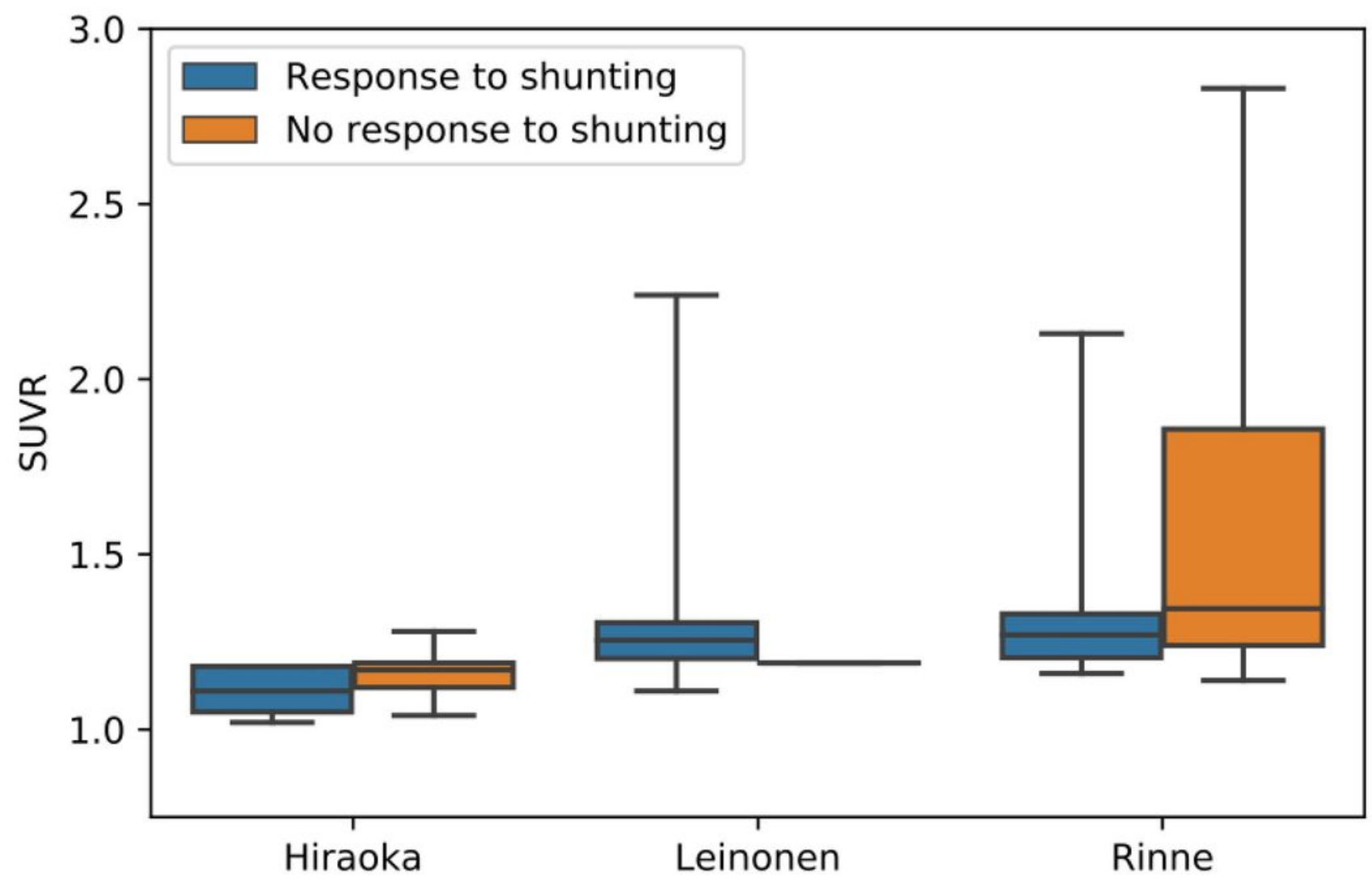

Figure 2

Box and whisker plot of SUVR values for patients with and without a response to shunting

\section{Supplementary Files}

This is a list of supplementary files associated with this preprint. Click to download.

- supplementaryinformation.docx 